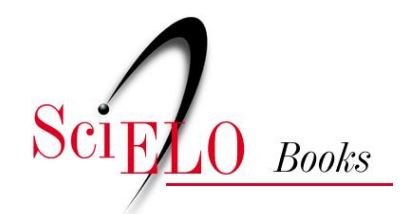

\title{
O Satã de John Milton
}

\author{
Fabiano Seixas Fernandes
}

\section{SciELO Books / SciELO Livros / SciELO Libros}

FERNANDES, FS. O Satã de John Milton. In MAGALHÃES, ACM., et al., orgs. O demoníaco na literatura [online]. Campina Grande: EDUEPB, 2012. pp. 125-137. ISBN 978-85-7879-188-9. Available from SciELO Books < http://books.scielo.org>.

\section{(c) (1) @()}

All the contents of this work, except where otherwise noted, is licensed under a Creative Commons Attribution-Non Commercial-ShareAlike 3.0 Unported.

Todo o conteúdo deste trabalho, exceto quando houver ressalva, é publicado sob a licença Creative Commons Atribuição Uso Não Comercial - Partilha nos Mesmos Termos 3.0 Não adaptada.

Todo el contenido de esta obra, excepto donde se indique lo contrario, está bajo licencia de la licencia Creative Commons Reconocimento-NoComercial-CompartirIgual 3.0 Unported. 


\title{
O Satã de John Milton
}

\author{
Fabiano Seixas Fernandes $(U F C)^{5}$
}

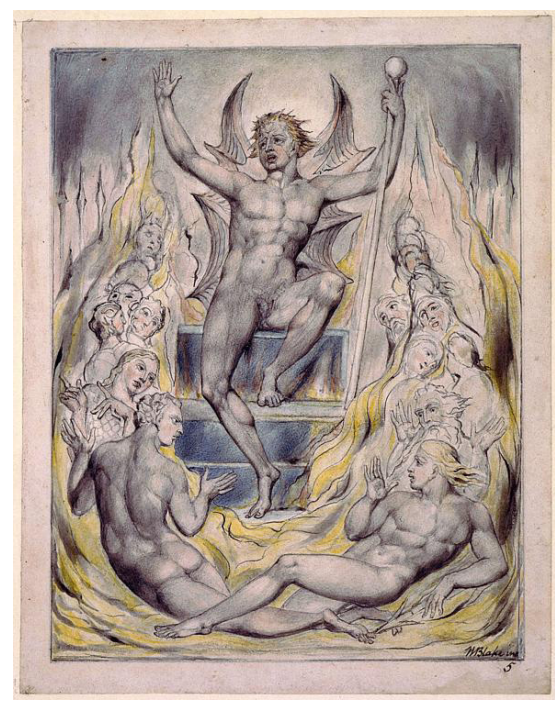

Uma das primeiras discussões que suscita a leitura do poema épico de John Milton (1608-74), Paradise Lost (1667; 2.ed.rev.1674), é o papel que Satã nele desempenha. Sua centralidade inicial e a visão favorável que dele tiveram alguns críticos (em especial, os românticos ${ }^{6}$ ) parece alçá-lo à condição de herói do épico. No que segue, apresento uma breve revisão

5 Possui graduação em Licenciatura em letras: inglês (1999) e Doutorado em Literatura (2004), ambos pela Universidade Federal de Santa Catarina. Atuou como Professor Substituto na mesma instituição (2008-9). Atualmente, é professor de Língua Inglesa e Literaturas pela Universidade Federal do Ceará. Email: fbnfnds@gmail.com.

6 Para um comentário acerca do papel da crítica romântica de Satã, ver Steadman: 1976, pp. 258-60. 
da crítica recente acerca do Satã presente em Paradise Lost (com especial ênfase em publicações em periódicos) ${ }^{7}$; a discussão formal do papel de Satã dentro do poema dará vazão a uma descrição da personagem, organizada a partir de duas estratégias recorrentes de Milton para apresentá-la.

De fato, é opinião difundida entre os críticos que os primeiros dois livros de Paradise Lost parecem estabelecer Satã como herói (ver, por exemplo, Hughes: 1957, p.177). Com a perspectiva destes dois livros centrada no Inferno ${ }^{8}$, observamos a agonia dos demônios (I.60-77, p.213) ${ }^{9}$; seu reerguer-se da torrente de lava (I.331-63, pp.219-20); sua proeza em construir para si um palácio (I.671-751, pp.228-30) e explorar os recursos do Inferno (II.570-628, pp.545-7), buscando superar como lhes for possível a perda de sua antiga glória (II.521-69, pp.244-5); sua aparentemente ponderada discussão acerca de como vencer um oponente a quem descrevem como tirano (II.01-506a, p.232-44). Não são, ainda, para o leitor, propriamente demônios, mas anjos menos lustrosos, empobrecidos em glória por uma derrota.

Satã é certamente o cerne desta descrição. Assistimos sua figura magistral inicialmente prostrada se reerguer da torrente de fogo (I.22130, p.217); ouvimo-lo esconder a própria dor e falar orgulhosamente a Belzebu (I.190-1, p.216) e, em seguida, às tropas (I.315-30, p.219), que, segundo afirma, preferiram-no e o apoiaram (I.101-5a, p.214), e precisam de sua voz para recuperar o moral (I.272b-82, p.218); sentimos sua

7 Os artigos aqui citados - compondo uma seleta certamente parcial de textos versando especificamente sobre o Satã de Paradise Lost—foram primeiramente coletados através de consulta à base virtual de dados do periódico Milton Quarterly, levando-se em consideração principalmente os publicados a partir dos anos 90; em segundo lugar, buscou-se o mesmo tipo de artigo junto ao portal Periódicos CAPES (http://www.periodicos.capes. gov.br/), com foco no mesmo período. Steadman (1976) apresenta uma extensa revisão de literatura acerca da figura de Satã em Paradise Lost de um período anterior àquele em que me concentrei. Agradeço a Daniel Hight Moore Jr por haver me facultado acesso tanto à base de Milton Quarterly quanto ao artigo de Steadman.

8 O que não significa que Milton neles se exima em absoluto de nos direcionar acerca de como deveríamos interpretar Satã. Alguns críticos, porém, prefeririam minorar a importância destas interferências diretas—como, por exemplo, A. J. A. Waldock (apud Steadman: 1976, pp.263-4).

9 Em todas as referências a Paradise Lost, ofereço inicialmente o livro (em numerais romanos) e os versos (em arábicos); a seguir, o número de página pela edição de Hughes (1957). 
inabalável e consciente vontade (I.157-91, pp.215-6); ouvimo-lo aceitar posição de liderança entre os anjos caídos (II.18-25, p.232), declarando que sua tarefa é ainda mais árdua que a deles (razão pela qual não teme ser destronado) (II.24a-35a, pp.232-3); finalmente, vemo-lo se oferecer para se aventurar sozinho no Caos e em um mundo desconhecido, para confirmar os rumores da criação de um novo mundo e de novos seres (II.450b-66a, pp.242-3).

Devido a esta apresentação inicial, é a missão de Satã que nos é inicialmente apresentada como a missão "épica" do poema: desbravar um mundo novo em sua luta contra o Criador. Esta missão faz com que desempenhe papéis semelhantes aos de heróis da épica clássica: guerreiro intrépido (lembrando Aquiles ou Heitor), líder militar (como Enéias), estrategista (como Odisseu), viajante (como todos os três), e mesmo, como aponta Steadman, espião e mestre em disfarces (como Odisseu) (1976: p.269). A ira de Satã —ultrajado pela ascensão do Filho-é semelhante à de Aquiles; sua busca por um novo lar (o novo mundo) em meio ao Caos ecoa a de Enéias, e sua astúcia a de Odisseu.

Contudo, o terceiro livro se inicia com Deus, e seu discurso auto -explanatório (III.80-134, pp.260-1) coloca Satã sob outra perspectiva: um viajante solitário cruzando o Caos sem saber que é observado, sem saber que essa viagem lhe está sendo permitida pelos poderes contra os quais se rebelara (I.211b-20, pp.216-7); alguém cujos planos estão frustrados de antemão, pois previstos desde a Eternidade pela inteligência que tudo criou e sabe (III.77-8, p.260). Já ao final do segundo livro, conhecemos o incesto de Satã com sua filha (Pecado), gerando seu filho/ neto (Morte) (II.648-814, pp.247-51), guardiães das portas do Inferno (II.850-2, p.252). Ao chegar à Terra-após promessas a Pecado e Morte (II.816-44, pp.251-2), ao Caos e à Noite (II.970b-87, p.255), disfarces (III.636-44, p.274) e mentiras ${ }^{10}$ —, veremos seus inúmeros solilóquios

10 A opinião é de Hillier (2009: p.19): para poder viajar, Satã promete ao Caos não invadir seu reino (já invadido pelas criações de Deus); mais tarde, porém, Pecado e Morte constroem uma ponte entre o Inferno e a Terra para mais fácil tráfego dos demônios (X.285b-305, p.413), o que quebraria a promessa de seu pai/amante/avô, avançando sobre os já decrescentes domínios do Caos. É fato que Satã aceita feliz a obra dos consócios (X.385-93a, p.415), mas não a ordenou; não podemos afirmar que haja quebrado explicitamente sua promessa ao Caos. Assim, atesto a opinião de Hillier, mas faço uma ressalva à evidência textual que apresenta. 
(IV.32-113, pp.278-80; IV.358-92, p.287; IV.505-35, p.290; IX.99178, pp.381-3; IX.473-93, pp.389-90): em sua solidão física, seu desespero fica aparente em seu primeiro momento de fraqueza, quando cogita inclusive o arrependimento (IV.79-80, p.279), e revela ser a "tirania" divina não mais que uma ação de graças, honrosa a quem a recebe tanto quanto a quem a oferece (IV.42b-8a, p.278); também a felicidade conjugal de Adão e Eva o aguilhoa em sua solidão desejante e frustrada (IV.505-11, p.290); sente por um momento compaixão e respeito por aqueles a quem se resolve a destruir (IV.361-2a, 373b-6a, 388-92, p.287). Em sua primeira tentativa, havendo habilmente aprendido algo acerca das criaturas cuja ruína busca (IV.514-22a, p.290), os anjos vigilantes o encontram transformado em sapo a sussurrar no ouvido de Eva (IV.800, p.297); veremos seu orgulho ferido ao não se reconhecido pelos anjos que o descobrem (IV.283-43, pp.297-8), e sua primeira fuga (IV.1013-5, p.302). Quando Rafael fizer seu relato da Guerra Celeste aos primeiros pais (V.563-907 e VI, pp.315-43), observaremos Satã novamente como líder militar das massas angélicas (desta vez em ação); veremos suas primeiras derrotas (VI.189-98a, p.328; VI.296-334, pp.330-1)—os primeiros indícios para ele e para nós de que sua força não é o que julgava ser, e que os anjos fiéis, imunes à dor, têm vantagens físicas sobre ele-, sua tentativa de reanimar suas tropas (VI.418-45, pp.333-4) e sua invenção de uma arma (o canhão) para o segundo dia de combates; antes do novo combate, veremos sua postura pouco digna ao mentir uma trégua para esconder sua invenção (VI.558-67, p.337); durante o combate, fará pouco dos inimigos temporariamente abalados pelo poder do canhão (VI.609-27, p.338). Finalmente, observaremos o Filho encher de terror as tropas revoltosas, que por si se jogam no abismo para fugir de uma visão que aos demais anjos enche de maravilha (VI.824-66, pp.343-4). (É a ira do Filho que de fato se assemelha à do Aquiles que volta à batalha, após a morte de Patroclo; a Satã, que sequer pode desafiá-lo a combater homem-a-homem, não caberia o correlato de Heitor.) Quando Satã retornar por si à cena, cruzará numa famosa jornada a Terra por "sete noites contínuas" (IX.48-86, pp.379-80), fugindo da luz e ziguezagueando, até finalmente escolher a serpente como instrumento para tentar Eva (IX.85b-6, p.380; IX.532-781, pp.391-6). Após a queda da humanidade, Satã estará triunfal, retornando ao Inferno para se gloriar de sua conquista (X.460-503, pp.417-8). Neste momento, vemo-lo 
pela última vez, transformado em serpente, rastejando no chão junto a seus asseclas, abrasado por fome e sede, e por elas compelido a comer frutas fictícias sabendo a cinza (X.504-84, pp.418-20).

Como apontam os críticos (McQueen: 1970 em particular $^{11}$ ), e como o resumo acima deixa entrever, Milton constrói uma imagem inicial de Satã que pretende desfazer ao longo do épico. Ao longo de Paradise Lost, Satã é exposto como um anjo vaidoso, incapaz verdadeiramente de frustrar os desígnios divinos, e cujas ações são toleradas por Deus somente para serem punidas quando bem lhe aprouver (III.211b-20, pp.216-7). Satã é progressivamente degradado (Waldock apud Steadman: 1976, p.263; Hughes: 1957, p.177), ou (o que seria mais ao gosto de Milton) se degrada a si mesmo.

Como isso é feito? Em primeiro lugar, através de uma mudança de ponto-de-vista. McQueen (1970: p.60) crê que a perspectiva fechada dos dois primeiros livros vai se abrindo com o desenrolar do poema, de modo que a personalidade de Satã e sua real condição se mostram por completo, até sua última e mais humilhante aparição, transformado em serpente. Assim, com o acréscimo de dados vindos de outras fontes-os monólogos de Satã, os discursos de Deus sobre como reverterá a revolta de Satã em benesses aos homens, o relato da Guerra Celeste feita pelo anjo Rafael a Adão e Eva-podemos reinterpretar a impressão forte causada pelos primeiros livros. Por sua própria confissão, seu companheirismo inicial redunda em sedução de seus companheiros (IV.83, p.279), e a tirania divina oferece muito mais do que exige (IV.42-8, p.278); a descrição feita por Rafael da guerra nos céus mostra que suas táticas são traiçoeiras (mentir, esconder armas); mostra ainda que sua destreza militar é menor do que dá a entender, uma vez que a própria queda o tornou mais vulnerável e propenso à dor-essas derrotas militares o farão futuramente menos propenso ao embate que ao embuste-; sua coragem ao se aventurar sozinho pelo Caos pode ser então reinterpretada como vaidade; sua descrição de sua "eleição" por seus pares é

11 McQueen de fato avança essa ideia em outro artigo que não o citado aqui; neste, porém, resume-a como segue: "In an earlier paper, I suggested that in Book I [...] Milton's use of a limited point of view [...] deliberately distorts the action to establish Satan initially as a serious adversary of God, only to reveal through a gradual widening focus the falsehood of such an assumption" (1970: p.60). 
comprometida por sua confissão de que os seduziu, e mais ainda pelo fato de que é oriunda de Deus, que o havia colocado acima dos anjos que convencera e comandara à rebelião (II.18-9, p.232). Embora sincera em certa medida (IV.86-9, p.279), sua descrição das agruras da liderança é preventiva de traição, uma vez que é o próprio Satã um insurreto; as dúvidas que lança publicamente acerca do direito de Deus a reinar nos céus e de seu poder criador (V.853-66a; p.322) são contraditas por sua plácida aceitação dos mesmos quando está só (IV.43, p.278) ${ }^{12}$.

Em segundo lugar, inúmeros críticos apontam a pesada labuta intertextual de Milton. Satã é aproximado de diversas figuras da mitologia clássica, seja via símile, seja pela apropriação recreativa que Milton faz de certos trechos de obras da Antiguidade clássica e da Idade Média; quando vistas mais de perto, as comparações são negativas em ao menos um dos dois sentidos:

A comparação desfavorece Satã por semelhança ou diferença. ${ }^{13}$ Cito alguns estudos. Maggie Kilgour (2008) compara o papel desempenhado por Satã em Paradise Lost ao de Juno na Eneida:

Like Virgil's Juno, Satan both sets the plot in motion and then tries to delay its inevitable, ordained end. Juno and Satan are both associated with confusion, transgression, and boundary breaking [...]. They thus oppose the figures of Jove and Jesus, who, as the Son's appearance in Paradise Lost book 6 also indicates, are both connected with order, closure, and the setting of limits through discrimination and differentiation. (2008, p.654.)

12 Embora seja fato que sua opinião oscile mesmo quando está só. Por exemplo, seu primeiro monólogo no livro IX se inicia com um elogio à Terra e termina fazendo dela pouco. Certamente, o reconhecimento se dá em um momento inicial do monólogo; Satã é momentaneamente abalado por dúvidas também quando vê Eva e se deixa levar por sua beleza (IX.444-72, p.389). Quando se torna mais autoconsciente, porém, retoma sua atitude desafiadora-o que talvez indique que é uma tomada de atitude, não uma postura natural e sincera. Talvez possamos inferir disso que tamanha é, para Milton, a bondade e a generosidade divinas, que mesmo resisti-la se torna uma tarefa penosa, feita a muito custo.

13 A aproximação entre Satã e Tideu se dá através de uma personagem intermediária, sendo que Tideu nunca é mencionado em Paradise Lost. Essa cadeia de transferências (porque Tideu é como Briareos e Briareos é como Satã, Satã é como Tideu) parece exigir demais mesmo de um leitor familiarizado com os intertextos de Milton. 
Ambas as personagens apresentam emoções destrutivas, e estão relacionadas à procrastinação de eventos pré-determinados—a fundação de Roma por Enéias e a redenção da humanidade - aos quais não podem evitar; ao final, evidencia-se que suas tentativas de interferir acabam por serem instrumentais aos desígnios superiores:

The end of the narrative [da Eneida] thus seems to reaffirm a hierarchical cosmic order, in which reason prevails over passion, male over female, epic over romance, telos over suspense. What appeared to be a dualistic world, caught in a struggle between two equal antithetical principals, is resolved through subordination [...] (Kilgour: 2008, p.656.)

John Mulryan (2005) explora o óbvio intertexto entre o nascimento de Pecado e o de Palas Atena-ambas nascidas adultas das respectivas cabeças de Zeus e Satã. Segundo Mulryan, "whether the myth of Athenas's birth is interpreted positively or negatively, it still redounds to the discredit of Satan, undermining his self-esteem with scorn, derision, and contempt" (p.16). Mulryan se baseia na interpretação dada ao mito do nascimento de Atena por três mitógrafos do século XVI: dar à luz é um processo femininzante (e extremamente doloroso) tanto para Zeus quanto para Satã, que os submete às dores do parto; finalmente, enquanto Zeus dá à luz o conhecimento, Satã não gera senão ignorância.

Irene Samuel relaciona a transformação final de Satã em serpente aos procedimentos alegóricos de Dante na Comédia: "Only Dante could have suggested to Milton the idea of having the scene represent the penalty exacted by divine justice - that the criminal must go on being and doing involuntarily what he formerly was and did by choice" (apud Butler: 2006, p.148).

Phillip Cardinale (2003) e Katherine Calloway (2005) comparam Satã e Enéias. Cardinale comenta I.125-6, passagem na qual um comentário acerca de Satã (que esconde o próprio desespero enquanto fala a Belzebu) parafraseia um comentário presente na Eneida acerca de Enéias (que também tenta esconder suas dores ao se dirigir às tropas):

The allusion ennobles the false face that Satan puts on to cheer his troops. The substance of Satan's speech echoes that of Aeneas in themes of destiny and perseverance. The difference is that where Aeneas urges faith in divine providence, Satan 
exhorts divine vengeance. Milton thus empowers Satan with the political acumen of Virgil's hero, but at a subtler level reminds the reader that Satan lacks Aeneas's defining trait, piety. (Cardinale: 2003, p.183.)

Como, no trecho em questão, Satã fala não às tropas, mas exclusivamente a Belezebu, Calloway acrescenta outra negativa: "he appears to be pulling himself together rather than trying to boost the morale of his followers" (2005, p.84).

Além desta, Calloway abordará duas outras passagens em que Milton parafraseia a Eneida de modo a suscitar a comparação entre Satã e Enéias - em todas, a atitude de Enéias difere da de Satã, enfatizando os deméritos deste. No trecho em que Eva come a maçã, a descrição do estremecimento da terra frente ao crime da mulher (IX.781-3, p.396) é oriunda de descrição semelhante quando do casamento da rainha Didone e de Enéias em uma caverna. Satã, aqui, incorpora tanto o papel de Enéias como amante como o de Vênus, que deseja a ruína de Didone (Calloway: 2005, p.86). Finalmente, o aparecimento de Satã em seu trono em meio a uma nuvem no Inferno (X.449-51, p.417) lembra a igualmente nublada aparição de Enéias a Didone, ocasionada por Vênus. Calloway comenta:

Satan wills his own concealment in, and emergence from, the cloud. Aeneas thus submits again to the will of someone greater [Vênus] while Satan refuses to concede the existence of such a person. This difference in attitude is evident in the way each behaves after his miraculous appearance. Satan immediately begins to boast, not entirely truthfully, of his many brave exploits and the success of his journey. Aeneas, on the other hand, shining and god-like as he is, describes his band as worn-out and unable even to thank Dido properly for her welcome. As was the case when both Satan and Aeneas suppressed despair in order to speak courageously, Satan's tone is arrogant while Aeneas' is forbearing. (2005, p.87.) 
Finalmente, George F. Butler (2006) traça uma cadeia de relações entre os Briareos (monstro gigantesco de cinquenta cabeças e cem braços) e Tideu (chefe militar retratado na Tebaída de Estácio, que come o cérebro de Melanipo, morto em combate) e Satã - servindo-se, para isso, de símiles presentes na Eneida, na Tebaída e na Comédia e que seriam direta ou indiretamente retomadas em Paradise Lost ${ }^{14}$.

A comparação demonstra a superioridade do ponto-de-vista cristão frente aos valores da épica clássica ${ }^{15}$. Apesar de seu enorme conhecimento

$14 \mathrm{O}$ método de Butler me parece falho, por isso o comento à parte. Segundo Butler, "Milton's comparison of Satan to Briareos reminds us that Statius had compared Tydeus to the same monster. And so Satan is indirectly related to Tydeus through Milton's simile" (2006, p.140, grifo meu). Ou seja, ao ler a símile de Milton (Satã é como Briareos), o leitor deveria se lembrar de outra, presente na Tebaída (Tideu é como Briareos), para inferir uma terceira, intertextual e indireta (Satã é como Tideu). Vejo dois problemas aqui:.

15 É necessário que nos indaguemos acerca dos limites da símile. Creio que Butler transfere características demais de uma personagem a outra. Vejamos: Virgílio compara Enéias em combate a Briareos em combate quanto a poder bélico; Estácio compara Tideu em combate a Briareos em combate quanto a tamanho (aqui, o gigantismo é fácil sinônimo de poder bélico); finalmente, Milton compara Satã a Briareos quanto a tamanho (sem, porém, conotação de poder bélico: assim como Satã está neste momento prostrado na torrente de lava, creio ser lícito imaginar Briareos prostrado ao chão após sua derrota por Zeus). Butler deseja que, da comparação física entre Satã e Briareos, possamos inferir uma comparação moral entre Satã e Tideu: Satã tem o mesmo tamanho de Briareos; Briareos é ímpio como Tideu; logo, Satã é ímpio como Tideu.

É lícito compararmos moralmente personagens comparadas fisicamente? Se assim for, a impiedade de Briareos também deveria tocar a Enéias, posto que ambos são comparados na Eneida; dada, porém, a descrição criticamente pacífica de Enéias como pius, Butler (que reconhece a símile) não faz a transferência da igualdade em destreza bélica à correção religiosa e moral neste caso.

A isso se acresce o fato de que, para embasar sua cadeia de símiles, Butler afirma que a fonte de Milton para "Satã é como Briareos" é a Tebaída, não a Teogonia: na Eneida e na Tebaída, Briareos é descrito como inimigo de Zeus, contrariamente ao que ocorre na Teogonia e na Ilíada (Butler: 2006, pp.135-40). Não vejo razão para isso; apesar de a caracterização de Briareos em Paradise Lost estar bastante próxima à presente na Tebaída, Milton não poderia simplesmente esquecer ou ignorar seu conhecimento da Teogonia ao escrever.

Certamente, trata-se de três personagens que se revelam ímpias em situações de combate: Satã se rebelara contra Deus, Briareos contra Zeus e Tideu canibalizara um inimigo morto-esses fatos, por si, permitiriam comparação. Mesmo assim, creio que as comparações de Butler não podem ser tomadas como evidência certeira das fontes textuais de Milton, muito menos como chaves de interpretações propositais do poeta, embora, como comparações originais, iluminem nossa compreensão de Satã 
clássico e do respeito que nutre por autores clássicos, Milton também tomará parte da revisão de seus valores a partir da perspectiva cristã.

Um dos mitógrafos mencionados pelo supracitado estudo de John Mulryan (2005: pp.19-20) expõe o ridículo de Zeus dando a luz ao Conhecimento na ferraria de Hefesto, e com a ajuda deste; os pagãos, mesmo quando produzem conhecimento, não conseguem fazê-lo fluir naturalmente (i.e. pela boca), tendo de abrir à força um outro orificio para que saia. $\mathrm{O}$ aspecto potencialmente risível do nascimento de Atenas, apontado pelo mitógrafo, poderia ser transferido talvez ao nascimento do Pecado da cabeça de Satã.

Este tipo de contraste, porém, é comentado normalmente quando os críticos enfocam a relação entre Satã e o Filho. Aventando uma opinião difundida entre a crítica, Butler comenta que Paradise Lost apresenta o contraste entre o "classical heroism of Satan" e o "Christian heroism of the Son” (2006, p.134). Em artigo específico comparando Paradise Lost e a Eneida, Butler comenta que o Filho é quem mais se aproxima de Enéias, embora as qualidades menos louváveis do herói troiano estejam presentes em Satã (Butler: 1997 apud Calloway: 2005, p.83). Também Calloway, ao tratar do paralelo entre as personagens de Enéias e Satã, conforme exposto acima, procura demonstrar que Milton aproxima Satã de Enéias para que suas diferenças sejam enfatizadas (2005, p.82)—o que contaria pejorativamente para Satã. Rebaixar Satã através do uso de intertextos-especificamente de Enéias, o herói clássico cuja pietas mais se aproxima dos valores cristãos $^{16}$, mas que nem por isso deixa de ser e agir ocasionalmente como pagão—cumpre não apenas a função de caracterizar o quedo arcanjo como personagem, mas também a de contrastar a moral e os métodos do heroísmo tradicional aos do heroísmo

16 Calloway afirma que Enéias "fits neither the classical nor the Miltonic ideal of a hero"; para ela, a grande diferença entre Satã e Enéias reside no fato de que "Aeneas accepts and makes the best of those situations into which he is thrown by fate and the gods, while Satan fiercely opposes, and indeed denies, any authority that supersedes his own". Também afirma que, ao escolher Enéias como modelo para imitação na construção de Satã, Milton "argues that even the most Christian of all pagan heroes fails to realize this higher standard" (todas as citações Calloway: 2005, p.88). Apesar de não negar a validade interpretativa da última asserção, confesso ter certa dificuldade em compreendê-la como um desejo direto de Milton sem conhecimento de evidência direta de que Milton considerasse de fato Enéias como "the most Christian of all pagan heroes". 
cristão ao quais Milton deseja exaltar: "the better fortitude / Of Patience and Heroic Martyrdom” (IX.31-2, p.379).

O estudo de Russell M. Hillier (2009) acerca de "fraud and force"as duas táticas militares comumente empregadas no heroísmo clássico, cujas mais puras manifestações são exemplificadas pela sanha assassina de Aquiles e pelos ardis de Odisseu-demonstra a constância dessas atitudes na fala e nos atos de Satã, bem como nos comentários acerca destes feitos por Milton:

Force and fraud, I am arguing, can be seen to relate to the Satanic heroic mode across Paradise Lost and Paradise Regained as a pejorative revaluation of both the ancient heroic code-as ancient epic is arguably foundational for the force-fraud collocation - and the Renaissance political philosophies of Machiavelli and Milton's contemporary, Thomas Hobbes. Set against the Satanic mode, an opposing Messianic mode of heroism can be evinced, the revealed Miltonic hero, who is exemplary, if not to a nation, then to Milton's readers, fit though few. (2009, pp.17-8.)

Finalmente, além de seu conhecimento de literatura clássica, Milton também usa seus vastos conhecimentos geográficos para demonstrar a decadência física e moral de Satã. Em seu estudo, Sherry Lutz Zivley descreve a supracitada a rota da Satã na escuridão após haver fugido do Éden e antes de decidir encarnar na serpente para tentar Eva (IX.48-86, pp.379-80), chegando à seguinte conclusão:

Having determined to rebel against God, Satan is no longer capable of being straightforward-not even in his travels. He cannot move with clear direction. Instead, he is driven with an careening [sic] frenzy. Although God and the angels can travel between Heaven and earth with lightning speed without assistance, Satan needs longer to find his way to Eden than God needed to create the earth. Yet the analogy with the seven days of creation is significant. In seven days God created the world and rested. But in the seven days of Satan's equinoctial 
and colurian orbits, he accomplishes nothing. $\mathrm{He}$ ends up at exactly the spot in the universe from which he began. And he certainly finds no rest. (1997, pp.134-5.)

Ademais, os críticos apontam o uso instrumental que Satã faz de $\operatorname{todos}^{17}$, seu orgulho desmesurado, seu potencial destrutivo e autodestrutivo. Rejeitando a autoridade divina, a fonte de toda a vida e de toda a criação, Satã pode apenas se isolar em si mesmo, em sua vontade. E essa vontade encontra pouca escolha senão ser oposta à do Criador-daí sua propensão ao ódio, à destruição e a ruína, de si tanto quanto do resto. Seu castigo final, convertido em serpente, é alegórico à maneira de Dante (conforme aponta Irene Samuel no estudo citado por Butler [2006]). O bravo movimento de se erguer das chamas e se desprender de correntes por um ato volitivo acima da própria dor em sua primeira aparição contrasta com seu rastejar involuntário e transformado em serpente em sua aparição final. Sua vontade, que até então o guiara, revela-se pelo que é: pulsão incontrolável que leva à frustração e à morte (a fruta com aparência de vida, mas com sabor e textura de cinzas).

17 Hillier (2009) cita um estudo de Simone Weil (1956) acerca da Ilíada, no qual a filósofa advoga ser força o conceito central do épico homérico, e a descreve como sendo "that $x$ that turns anybody who is subjected to it into a thing" (Weil: 1956 apud Hillier: 2009, p.29). Hillier acredita que "Milton's Satan fits Weil's category $x$, because he understands all matter and phenomena that are creative expressions of God's intrinsic goodness to be functional and reducible to instruments only valid in accomplishing his own self-glorification. The angels Lucifer leads into battle, the complicity of Sin and Death, his pact with Chaos and eternal Night, and the innocence of Adam and Eve are for Satan all ontologically degradable to means used by which he might set himself higher. [...] Like Weil's intoxicated Homeric hero, a proponent of desolating force, Milton's characterization of Satan delineates the deleterious psychological development of an essentially unattractive 'hero' for whom 'onely in destroying I finde ease', a debased figure tragically divided against everyone, everything, and even itself' (2009: p.29). 


\section{Bibliografia}

Butler, G. F. The fall of Tydeus and the failure os Satan: Statius' Thebaid, Dante's Commedia, and Milton's Paradise Lost. In: Comparative Studies in Literature, vol.43, n.01-2. Penn State University Press, 2006, pp.134-52.

Calloway, K. Beyond parody: Satan as Aeneas in Paradise Lost. In: Milton Quarterly, vol.39, n.02. Wiley, 2005. pp.82-92.

Cardinale, P. Satan as Aeneas: An Allusion to Virgil in Paradise Lost. In: Notes and Queries, n. 248. Jun/2003. p.183.

Hillier, R. M. "By force or fraud / Weening to prosper": Milton's Satanic and Messianic modes of heroism. In: Milton Quarterly, vol.43, n.01. Wiley, 2009. pp.17-38.

Kilgour, M. Satan and the wrath of June. In: English Literary History, vol.75, n.03. The John Hopkins University Press. outono/2008. p. 653-671.

McQueen, W. A. “The hateful siege of contraries": Satan's interior monologues in Paradise Lost. In: Milton Quarterly, vol.04. n.04. Wiley: dez/1970. p. 60-65.

Milton, J.; Hughes, M. Y. (ed.). Complete Works and Major Prose. Indianapolis: Hackett, 1957, reimp.2003.

Mulryan, J. Satan's headache: the perils and pains of giving birth to a bad idea. In: Milton Quarterly, vol.39, n.01. Wiley, 2005. p.16-22.

Shawcross, J. T. An early view of Satan as hero of Paradise Lost. In: Milton Quarterly, vol.32, n.03. Wiley: out/1998. p. 104-105.

Steadman, J. M. The idea of Satan as the hero of Paradise Lost. In:

Proceedings of the Amerian Philosophical Society, vol.120, n.04 (Symposium on John Milton). 1976. p. 253-294.

Zivley, S. L. Satan in Orbit: Paradise Lost: IX: 48-86. In: Milton Quarterly, vol.31, n.04. Wiley: 1997. p. 130-136.

\section{Imagem}

Satã por William Blake. Disponível em http://escamandro.files.wordpress.com/2012/07/william-blake-satan-in-council.jpg, consultado em $07 / 10 / 2012$ 
